(C) 2017, American Psychological Association. This paper is not the copy of record and may not exactly replicate the final, authoritative version of the article. Please do not copy or cite without authors permission. The final article will be available, upon publication, via its DOI: $10.1037 /$ cpp0000187

\title{
Narrative Exposure Therapy with parents who have been traumatised \\ in pediatric settings: a case series
}

\author{
Gillian A. Colville \\ Paediatric Psychology Service \\ St George's Hospital, London, UK
}

Thank you to Bill Yule for introducing me to this treatment approach and to Glenda Fredman for her comments on earlier versions of this paper and her encouragement to write it in the first place.

Correspondence concerning this article should be addressed to Gillian A. Colville, Paediatric Psychology Service, $2^{\text {nd }}$ floor Clare House, St George's Hospital, Blackshaw Rd, London SW17 0QT. E-mail: gcolvill@sgul.ac.uk

\begin{abstract}
There is increasing evidence that a significant number of parents are affected by symptoms of post-traumatic stress and anxiety for many months after their child's serious illness or accident. It is important therefore that psychological treatments for use with this population are tried and evaluated for effectiveness with this population. The application of a new brief treatment, Narrative Exposure Therapy, is described here in relation to a case series of four parents who met criteria for post-traumatic stress disorder following their child's intensive care treatment. This approach, which has shown promise with other samples of people who have suffered repeated traumas, was associated with significant symptom relief (Cohen's $d=1.01-2.37$ ). The main themes that emerged in therapy are discussed, along with other treatment considerations.
\end{abstract}

Keywords: intervention; post-traumatic stress disorder (PTSD); anxiety; depression; NET 


\section{Narrative Exposure Therapy With Parents Who Have Been Traumatized in Pediatric Settings: A Case Series}

The possibility of being traumatized by the suffering of another has been more widely acknowledged since the extension of the criteria necessary for a diagnosis of Post-traumatic Stress Disorder (PTSD) to include vicarious trauma (American Psychiatric Association, 1994). One example of a situation in which a person may be severely traumatized, without actually being at risk physically themselves, is that of a parent witnessing the suffering of a child in a hospital context in the event of an accident or serious illness. There is a growing literature on the prevalence of post-traumatic stress symptoms in parents in pediatric settings and in particular those whose child's condition requires admission to intensive care (Balluffi et al., 2004; Bronner, Knoester, Bos, Last,\& Grootenhuis, 2008; Colville \& Pierce, 2012). As many as one in five parents in this situation report clinically significant rates of PTSD (Nelson \& Gold, 2012) and research shows that they are aware that they have a tendency to be over-protective for many months after their child's discharge (Colville et al., 2009). Furthermore, the evidence that children take longer to recover emotionally when their parents report a high level of post-traumatic stress symptoms (Landolt, Ystrom, Sennhauser, Gnehm, \& Vollrath, 2012) suggests that it is important to find ways to help such parents, not just for their sakes but also in the interests of promoting their children's psychological wellbeing.

\section{Narrative Exposure Therapy}

Traditional evidence-based treatments for PTSD have, for the most part, addressed single traumas and commonly focus on exposure to the most traumatic event experienced, but a novel approach Narrative Exposure Therapy (NET), which is manualized (Schauer, Neuner, \& Elbert, 2011), focuses instead on the value of integrating multiple traumatic experiences into the client's wider life story. NET was originally designed for use with survivors of multiple traumas, such as those experienced during war and after natural disasters, in situations where support services are in short supply and is informed by testimony therapy, narrative therapy and cognitive-behavioural exposure therapy. In a recent review comparing the results of 15 studies using NET to those of 32 using Prolonged Exposure Therapy, Morkved et al. (2014) found that NET was comparable in terms of effectiveness and had better drop-out rates. On the basis of this evidence the authors have called for more research evaluating its use with a wider range of populations and trauma types.

NET treatment is quite intensive in that it is usually scheduled at the frequency of two 60 to 90 minute sessions a week but it is of a similar overall length to other established PTSD treatments (National Collaborating Centre for Mental Health, 2005). In the first session the client is asked to relate a summary of their life up until the trauma. In subsequent sessions they are encouraged to talk through the most difficult parts of their experience in detail, paying attention to the thoughts, emotions and physical sensations they felt at the time, with the aim of helping them to uncover the 'fear network' of associations linked with their trauma memories (Schauer et al., 2011). The therapist takes detailed notes during each session and then reads them back aloud to the client at the start of each new session. This serves the functions of a) re-exposing them to the material; b) giving them the chance to correct any mistakes or add additional details and c) providing them the opportunity to reflect on and create new meanings in relation to their experiences, which can then be incorporated into the 
latest version of the account. Finally, with the help of the therapist, the client uses this account to construct their individual lifeline, illustrating the most notable high and low points in their life story with symbolic flowers and stones (see Figure 1). At the end of treatment they are given copies of the account and lifeline to keep.

It was decided to trial this approach with parents who had been referred for trauma symptoms in relation to their child's pediatric treatment, on the basis that a) NET was developed for use with people that have suffered repeated traumas, as is often the case with parents whose children have been critically ill; b) its focus on the whole story, as opposed to the worst event, might be more conducive to helping parents both process the wider context of the child's illness and better integrate previous traumatic events, which they are more likely to have experienced than non-symptomatic parents (Ozer, Best, Lipsey,\& Weiss, 2003) and c) it is reported to be well tolerated, with lower drop-out rates than other forms of therapy for PTSD.

In this paper the use of NET is described with four traumatized parents, following their child's PICU admission. The impact of this treatment approach on their psychological symptoms is examined, as are the main themes that emerged in the work and clinical implications for therapists.

\section{Method}

\section{Setting}

The setting was an inner city teaching hospital, within the UK National Health System (NHS), which has an embedded Pediatric Psychology Service (8.8 clinical psychologists) and a 12-bed PICU. The psychologist, who covers PICU on a half time basis, sees 40-60 referrals a year, with treatment costs covered by the hospital, as part of NHS public health provision. The nature of the referrals is comparable to that recently described in a similar context in a US unit, by Tunick, Gavin, DeMaso, \& Meyer (2013), but both the mortality rate (4\% in UK $\mathrm{v} 2.7 \%$ in US) and the proportion of PICU admissions referred to psychology $(10 \%$ in UK v $5 \%$ in US) are higher on the UK unit.

The clinical psychologist who delivered the treatment described below attended a training workshop organised by the developers of NET at the University of Konstanz in Germany. (Further details of training workshops in the United States and elsewhere are available at http://www.nvivo.org/.)

\section{Participants}

Four parents of children who had been treated in the PICU were referred for support. They all met DSM-IV criteria for PTSD on the basis of their questionnaire results and agreed to try NET as a way to address their ongoing distress. In two cases the parent had not been seen by the psychologist before (Cases 1 and 2) but the other two parents had been seen while their child was an inpatient and their symptoms were being monitored after discharge. The series comprised one father and three mothers, all of white Caucasian ethnicity. Main sample characteristics are given in Table 1. Reasons for referral to PICU and length of stay and were comparable to UK national data for this population, the majority of whom are aged under $5 \mathrm{y}$ (Paediatric Intensive Care Audit Network, 2015). 


\section{Measures}

Post-traumatic stress symptoms were assessed using the 49-item Posttraumatic Diagnostic Scale (PDS) (Foa,1996), which establishes whether someone meets the DSM-IV criteria for PTSD and measures the severity of their key symptoms of avoidance, reexperiencing and hyperarousal in relation to this diagnosis. Total scores, which range from 0 51, are categorized in terms of severity as follows: $>35=$ severe; $21-35=$ moderate/severe; 11 $20=$ moderate and $1-10=$ mild. The PDS is reported to demonstrate high internal consistency $(0.92)$ and good test-retest reliability $(0.83)$, as well as showing good agreement $(83 \%)$ with an independent PTSD diagnosis based on clinical interview (Foa, Cashman. Jaycox, \& Perry, 1997).

The Hospital Anxiety and Depression Scale (HADS) is a self-report questionnaire which is frequently used in community samples as a screen for mental health problems (Zigmond \& Snaith, 1983). It is made up of two separate scales, one measuring anxiety (7 items) and the other measuring depression ( 7 items), with responses weighted 0 to 3 for frequency. For each scale, scores of 8-10 indicate mild symptoms, 11-13, moderate symptoms, and $>=14$, severe symptoms. The HADS has been widely used internationally, has demonstrated good levels of internal consistency ( 0.93 for anxiety and 0.90 for depression) and test-retest reliability ( 0.54 for anxiety and 0.79 for depression) (Bjelland, Dahl, Haug, \& Neckelmann, 2002) and its factor structure has been confirmed in a number of different populations (Moorey et al., 1991).

\section{Analysis plan}

The analysis plan was to assess all three outcomes at baseline and again two and six months after treatment was completed. Visualization of the parents' symptom trajectories was used to determine whether there was evidence of a treatment effect as evidenced by a sustained drop in psychometric scores from the clinically significant to the non-significant range (Ernst, Barhight, Bierenbaum, Piazza-Waggoner, \& Carter, 2013). Further supporting anecdotal information, in the form of feedback regarding any changes parents noticed since treatment, was also sought. The sample size precluded formal statistics but effect sizes were computed using Cohen's $d(0.2-0.5=$ small effect; $0.5-0.8=$ medium effect; $>0.8=$ large effect $)$.

\section{Illustrative Case Study ${ }^{1}$}

Background. Johnny, a four year-old boy, was crossing the road on the way to school with his mother when he was hit by a van and sustained a serious fracture to his leg, as well as briefly losing consciousness. He was airlifted to hospital and his mother was escorted there by the police. She telephoned Steve, Johnny's father, from the back of the police car, distraught, and he then made his own way, by bus, to the hospital to join them.

Hospital Admission.Johnny was sent for X-ray on arrival. He was very distressed and confused initially but was relieved when his parents arrived. He spent a week on PICU recovering from surgery and was then moved to the surgical ward. Steve stayed overnight with him as his wife was heavily pregnant. In the second week, however, Johnny's condition deteriorated and he needed to be transferred back to PICU for 48 hours. In the following twoweeks on the ward, he had to undergo numerous painful procedures in relation to the management of his wounds which were distressing for him and also for his parents to witness. At the bedside nurse's request therefore, the psychologist met with the family twice for support. The focus of intervention at this stage was on promoting Johnny's parents' 
coping resources (Kazak et al.,2006) and teaching Johnny distraction techniques to help him manage his dressing changes.

Re-referral.Six months after Johnny's discharge, Steve mentioned in his son's orthopedic review appointment that he himself was regularly experiencing flashbacks, finding it hard to concentrate at work and had noticed his heart racing whenever he heard an ambulance siren or the phone rang. He was therefore re-referred to the PICU psychologist who found on subsequent assessment, at a separate appointment, that his levels of posttraumatic stress and anxiety were clinically significant.

Narrative Exposure Therapy.Steve was seen for six twice-weekly sessions of NET. In the first session he revealed that he had lost a classmate in a road accident when he was a child and that he had feared that Johnny, who he was born prematurely, would die. When Steve's distress rose in sessions he was encouraged to use simple grounding strategies, such as rising to a standing position in the room, to bring his immediate anxiety down before continuing the account. In the final session, with the help of the therapist he drew up a lifeline based on the final account (see Figure 1).

Follow-up.Steve's symptoms were monitored at regular intervals over the following year. Two months after treatment his symptoms were significantly improved, in that he was sleeping much better and no longer met criteria for PTSD. At six months, he reported that he felt closer to his son and was grateful for a new appreciation of the way in which recent events had triggered memories of earlier traumatic experiences. He was discharged at one year.

\section{Results}

\section{Quantitative Data}

Three parents completed their NE treatment within seven sessions. In the remaining case (Case 3) the therapy took ten sessions because of the high number of traumatic events that had occurred over the course of this child's lengthy admission. All parents completed questionnaires pre-treatment and two months post-treatment at a follow-up appointment. Additional scores were obtained from three parents at six month follow-up. (Case 1did not attend but later reported that their symptoms had continued to reduce steadily after treatment). Significant and sustained improvements in symptoms were reported, particularly in relation to post-traumatic stress and anxiety (see Figure 2). Mean (SD) scores fell between baseline and two months post-treatment as follows: from 20.75 (9.46) to 9.25 (7.27) for posttraumatic stress, $(d=1.36)$; from $14.25(4.27)$ to 8.25 (3.59) for anxiety $(d=1.52)$ and from 5.25 (3.69) to 3.75 (3.77) for depression $(d=0.40)$. They reduced further, as compared with baseline, by six months to 3.67 (1.52) for post-traumatic stress $(d=2.37) ; 5.00(d=2.15)$ for anxiety $(d=2.15)$ and $1.33(2.31)$ for depression $(d=1.01)$, such that by this stage none of the parents' scores were in the relevant clinical range. (The relatively smaller change in depression scores may relate to the fact that these symptoms were not particularly elevated at baseline, unlike these parents' symptoms of post-traumatic stress and anxiety.)

\section{Parents' Comments ${ }^{2}$}

Parents found it difficult to organize their memories initially but expressed relief when they had completed the account, consistent with the recent conceptualisation of PTSD as primarily a disorder of memory (Yule, 2014). The most striking aspect of their accounts was the power and particularly visceral nature of the feelings they articulated having at the time of their traumatic experiences: "In the ambulance I had the most painful and 
overwhelming feeling I have ever had in my life. It felt like being belted in the guts five or six times over - the feeling that I should have kept (child)safe." In addition all four parents expressed the strong fear that their child could have died: "I really thought (child) could die. I felt it physically. I felt a sort of internal shaking which was terrifying but which for some reason did not show on the outside. This is a feeling I have had since." This subjective perception has been found to be more predictive of later post-traumatic stress symptoms than measures of objective risk to the child (Balluffi et al., 2004).

Parents appreciated being provided with a concrete illustration of events, in the form of the lifeline, at the end of NET treatment, and spoke of a new understanding of the links between the traumatic events they had described and other events in their lives, such as the serious illnesses or deaths of loved ones in the past. They also commented on the value of recognizing that good things had happened during their child's time in hospital as well as bad, suggesting that they, like others in this situation, may have experienced a degree of posttraumatic growth (Colville \& Cream, 2009). Finally, at follow up, parents gave examples of situations they were able to tolerate with much less anxiety than before, such as travelling abroad with their family and managing their children's minor illnesses.

\section{Discussion}

The traumatized parents described in this case series had witnessed repeated examples of their children suffering sudden, life-threatening deteriorations and numerous, painful, treatment-related ordeals. The provision of NET was associated with prompt and significant reductions in their symptoms of post-traumatic stress. Furthermore, the available evidence suggested that, as Schauer et al. (2011) report, their symptoms continued to reduce in the months after treatment. Large treatment effects were seen both at two month and six month follow-up, in comparison with baseline scores. These findings also illustrate the importance of assessing co-morbid problems in traumatized patients as they suggest that this treatment, which targeted post-traumatic stress, also had a positive impact on symptoms of anxiety and depression.

Previously the evidence base for this approach has related mainly to its use with refugees or war-torn samples in developing countries (Robjant \& Fazel, 2010). This study adds to a growing literature which suggests that NET might be applicable with a wider range of trauma types than previously reported (Alghamdi, Hunt, \& Thomas, 2015; Campbell et al., 2016; Zang, Hunt,\& Cox, 2014).

\section{Therapist considerations}

In line with recent evidence favouring high frequency contact in therapy for PTSD (Gutner, Suvak, Sloan,\&Resick, 2016), the developers of NET recommend twice-weekly sessions, arguing that a frequency of less than weekly is unlikely to bring about the degree of immersion in the relevant traumatic memories that they believe is necessary for the technique to be effective (Schauer et al., 2011). This level of intensity may not suit everyone but there is evidence that patients offered intensive therapy report that the high pressure and pace improves their motivation and engagement, despite their initial misgivings about being overwhelmed (Bevan, Oldfield, \& Salkovskis, 2010). Whilst it has been our experience that only approximately half of those offered this or other forms of trauma focused therapy have ultimately agreed to formal input, to date no parent has dropped out of NET treatment. It remains to be seen whether this success will be maintained in a larger sample but it is 
consistent with evidence that NET is better tolerated than more traditional exposure therapy (Morkved et al., 2014) and contrasts with the experience of other trauma therapists working in real-world settings (Kehle-Forbes, Meis, Spoont, \& Polusny, 2016).

In relation to treatment fidelity, broadly speaking it was possible to maintain the frequency of sessions advised in the NET manual, although 3 of the total 29 treatment sessions offered needed to be rescheduled. However, although the developers recommend limiting the discussion of previous life events to the first session only, in practice this part of the treatment took two sessions in two cases (Case 3 and Case 4), because of the number of traumatic events experienced in the past.

Trauma work is generally acknowledged to be emotionally demanding and particularly challenging for therapists (Zoellner et al., 2011) but in relation to NET specifically there are additional challenges in terms of scheduling, both for the patient and for the therapist. Although no homework is set with this approach, the patient needs to clear their weekly timetable sufficiently to focus on the therapeutic work during sessions and to have time for reflection on it between sessions. In addition the therapist needs to allocate sufficient time between sessions to prepare the latest version of the narrative account, so that it is ready to be read out at the following session. This task, which can often take an hour or more after the first few sessions particularly, is more demanding than the simple transcription of session notes since the client's account is often very jumbled initially. The therapist needs to use their clinical judgment regarding the saliency of particular thoughts, events and feelings in order to decide what to include and what to leave out. In this way they help the client to construct a narrative that is both coherent and meaningful.

In relation to the wider implications for clinical practice, the length of time between the parents' traumatic experiences and their treatment is worthy of further comment here. The parents in this case series had been symptomatic for many months but had not received help earlier. This was partly because they hoped their symptoms would reduce over time, but also because they needed to adjust to the new demands placed on them by their child's medical condition, consistent with research suggesting that biological and social concerns need to be tackled before a parent has the energy to attend to their own psychological adjustment after a PICU admission (Atkins, John, \& Colville, 2014). However, the fact that the two cases who were already in contact with the psychologist were seen sooner suggests that ideally this group should be monitored routinely after discharge, particularly if they are found to be at high risk of developing PTSD (Samuel, Colville, Goodwin, Ryninks, \& Dean, 2015).

Decisions regarding whether and when to embark on an intervention such as NET require that the therapist establishes first that the parent's life situation is sufficiently stable for them to have the emotional space, as well as the time, available to confront their traumatic memories (Lab, Santos, \& Zulueta, 2008). In practice in pediatric settings this means that the timing of this intervention is dependent on the stability of the child's medical condition and therefore treatment can usually only take place some time after the child has been discharged from hospital.

Finally an argument could be made that this work might be more appropriately undertaken by a local adult therapist with experience of treating trauma. Indeed, even where the hospital reimbursement system allows for long term follow-up, the distance a parent lives from the hospital may make regular appointments difficult to attend, in which case it may well be more appropriate to refer them on to an appropriate local service. However, it is our experience that parents often report that their experiences are not well understood beyond the acute setting in which their child was treated and that they therefore really appreciate being offered this continuity of care. Provision of follow-up care such as this also reflects the 'systems-orientation' of pediatric psychology (Ernst, et al., 2013), in that it recognises the 
dependency of the child in this 'inseparable dyad' on the emotional wellbeing of the caregiver (Davidson, 2012).

\section{Limitations and Future Directions}

It is necessary to acknowledge the limitations of this small case series which may not be representative of other populations of parents of critically ill children. Also the fact that two parents had had previous contact with the psychologist, when their child was an inpatient, may have contributed to their positive outcomes and the lack of a control group meant that it was not possible to be certain that the improvements seen were attributable to the treatment provided. However, the length of time parents had been symptomatic, taken together with the promptness and enduring nature of the reduction in their symptoms, suggest that further evaluation of this technique with larger samples is warranted.

In terms of implications for clinical work in the future, although this study focused on the experience of parents of children who had been admitted to PICU, it is clear from the literature in this field that persisting symptoms of post-traumatic stress are also often seen in the children themselves, after critical care treatment (Colville \& Pierce, 2012; Nelson \& Gold, 2012). KidNET, a version of NET which has been adapted for use with younger patients by Ruf et al. (2008), might be useful to try with symptomatic children, perhaps as part of a more general support package aimed at helping them understand their condition. This approach might also be helpful with other groups who report high rates of post-traumatic stress in pediatric settings, such as the families of children with cancer (Alderfer, Cnaan, Annunziato,\& Kazak, 2005; Bruce, 2006) and other life-threatening conditions, or when the idea of incorporating traumatic events into the person's wider life story seems particularly appropriate or appealing.

Also the finding that delayed reactions are common in this population (Colville \& Pierce, 2012) suggests that families should be monitored for some time and might benefit from flexible services, which they can access when the time is right for them. Even in situations where there are insufficient resources available to provide therapeutic outpatient support for parents at the base hospital, pediatric psychologists could monitor parents by postal questionnaire after discharge and refer on any found to be symptomatic to appropriate local services or alert their primary physician to their psychological difficulties.

In conclusion, although it has been apparent for some time that PICU parents often suffer significant distress in relation to their traumatic experiences related to their child's treatment in the PICU, there is a dearth of information on how best to help them. This study adds to small literature on intervention in this field and, in doing so, goes some way towards meeting our moral obligation to provide services that better address their psychological needs (Hoehn, 2014).

\section{References}

Alderfer, M.A., Cnaan, A., Annunziato, R.A., \&Kazak, A.E. (2005).Patterns of posttraumatic stress symptoms in parents of childhood cancer survivors. Journal of Family Psychology, 19, 430-440. doi:10.1037/0893-3200.19.3.430

Alghamdi, M., Hunt, N., \& Thomas, S. (2015). The effectiveness of Narrative Exposure Therapy with traumatised firefighters in Saudi Arabia: a randomized controlled study. Behaviour Research and Therapy, 66, 64-71. doi:10.1016/j.brat.2015.01.008 
American Psychiatric Association. (1994). Diagnostic and statistical manual of mental disorders DSM-IV $\left(4^{\text {th }}\right.$ Ed). Washington, DC: American Psychiatric Association.

Atkins, E., Colville, G., \& John, M. (2012). A 'biopsychosocial' model for recovery: A grounded theory study of families' journeys after a Paediatric Intensive Care Admission. Intensive and Critical Care Nursing, 28, 133-140. doi:10.1016/j.iccn.2011.12.002

Balluffi, A., Kassam-Adams, N., Kazak, A., Tucker, M., Dominguez, T., \&Helfaer, M. (2004). Traumatic stress in parents of children admitted to the pediatric intensive care unit. Pediatric Critical Care Medicine, 5, 547-553. doi:10.1097/01.PCC.0000137354.19807.44

Bevan, A., Oldfield, V.B., \&Salkovskis, P.M. (2010). A qualitative study of the acceptabilityof an intensive format for the delivery of cognitive-behavioural therapy for obsessive-compulsive disorder. British Journal of Clinical Psychology, 49, 173191. doi:10.1348/014466509X447055

Bjelland, I., Dahl, A.A., Haug, T.T.,\&Neckelmann, D. (2002). The validity of the Hospital Anxiety and Depression Scale: an updated literature review. Journalof Psychosomatic Research, 52, 69-77.

Bronner, M., Knoester, H., Bos, A., Last, B., \&Grootenhuis, M. (2008). Follow-up after paediatric intensive care treatment: parental posttraumatic stress. ActaPaediatrica, 97,181-186.doi:10.1111/j.1651-2227.2007.00600.x

Bruce, M. (2006). A systematic and conceptual review of posttraumatic stress in childhood cancer survivors and their parents. Clinical Psychology Review, 26, 233-256. doi:10.1016/j.cpr.2005.10.002

Campbell, C.A., Albert, I., Jarrett, M., Byrne, M., Roberts, A., Phillip, P., . . Valmaggia L. (2016). Treating Multiple Incident Post-Traumatic Stress Disorder (PTSD) in an Inner City London Prison: The Need for an Evidence Base. Behavioural Cognitive Psychotherapy, 44, 112-117. doi:10.1017/S135246581500003X

Colville, G., \& Cream, P. (2009). Post-traumatic growth in parents after a child's admission to intensive care: maybe Nietzsche was right? Intensive Care Medicine, 35, 919-923. doi:10.1007/s00134-009-1444-1

Colville, G., Darkins, J., Hesketh, J., Bennett, V., Alcock, J., \& Noyes, J. (2009). The impact on parents of a child's admission to intensive care: integration of qualitative findings from a cross-sectional study. Intensive and Critical Care Nursing, 25, 72-79.doi: 10.1016/j.iccn.2008.10.002

Colville, G.A., \& Pierce, C. (2012). Patterns of post-traumatic stress symptoms in families after paediatric intensive care. Intensive Care Medicine, 38, 15231531.doi:10.1007/s00134-012-2612-2

Davidson, J. E. (2012). Time for a formal assessment, treatment and referral structure for families of intensive care unit patients. Critical Care Medicine,40, 1675-1676. doi:10.1097/CCM.0b013e318249594a

Ernst, M.M., Barhight, L.R., Bierenbaum, M. L., Piazza-Waggoner, C., \& Carter, B. D. (2013). Case Studies in Clinical Practice in Pediatric Psychology: the "Why" and "How To". Clinical Practice in Pediatric Psychology, 1, 108-120.

Foa, E.(1996). Posttraumatic Stress Diagnostic Scale Manual.Minneapolis, MN: National Computer Systems.

Foa, E., Cashman, L., Jaycox, L., \& Perry, K. (1997). The validation of a self-report measure of PTSD: The Posttraumatic Diagnostic Scale. Psychological Assessment, 9, 445-451.

Gutner, C.A., Suvak, M.K., Sloan, D.M.,\&Resick, P.A. (2016). Does timing matter? Examining the impact of session timing on outcome.Journal of Consulting and Clinical Psychology, 84, 1108-1115. doi:10.1037/ccp0000120 
Hoehn, K.S. (2014). Posttraumatic stress and technology: Do extracorporeal membrane oxygenation programs have an ethical obligation to provide ongoing psychological support for parents? Pediatric Criiical Care Medicine, 15, 180181.doi:10.1097/PCC.0000000000000045

Kazak, A.E., Kassam-Adams, N., Schneider, S., Zelikovsky, N., Alderfer, M.A., \&Rourke, M. (2006).An integrative model of pediatric medical traumatic stress.Journal of Pediatric Psychology, 31, 343-355. doi:10.1093/jpepsy/jsj054

Kehle-Forbes, S.M., Meis, L.A., Spoont, M.R.,\&Polusny, M.A. (2016). Treatment initiation and dropout from prolonged exposure and cognitive processing therapy in a VA outpatient clinic. Psychological Trauma, 8, 107-114. doi:10.1037/tra0000065

Lab D., Santos I., \& de Zulueta, F. (2008) Treating post-traumatic stress disorder in the 'real world': evaluation of a specialist trauma service and adaptations to standard treatment approaches. Psychiatric Bulletin, 32, 8-12.

Landolt, M.A., Ystrom, E., Sennhauser, F.H., Gnehm H.E., \&Vollrath, M.E. (2012). The mutual prospective influence of child and parental post-traumatic stress symptoms in paediatric patients.Journal of Child Psychology and Psychiatry,53, 767-774. doi:10.1111/j.1469-7610.2011.02520.x

Moorey, S., Greer, S., Watson, M., Gorman, C., Rowden, L., Tunmore, R. . . Bliss, J. (1991).The factor structure and factor stability of the hospital anxiety and depression scale in patients with cancer. British Journal of Psychiatry, 158, 255-259.

Morkved, N., Hartmann, K., Aarsheim, L.M., Holen, D., Milde, A.M., Bomyea, J., \& Thorp, S.R. (2014).A comparison of Narrative Exposure Therapy and Prolonged Exposure therapy for PTSD.Clinical Psychology Review, 34, 453467.doi:10.1016/j.cpr.2014.06.005

National Collaborating Centre for Mental Health(2005). Post-traumatic Stress Disorder: The Management of PTSD in Adults and Children in Primary and Secondary Care.(National Practice Guideline 26). London: Gaskell and British Psychological Society.

Nelson, L.P.,\& Gold, J.I. (2012). Posttraumatic stress disorder in children and their parents following admission to the pediatric intensive care unit: A review. Pediatric Critical Care Medicine ,13, 338-347.doi:10.1097/PCC.0b013e3182196a8f

Ozer, E.J., Best, S.R., Lipsey, L., \& Weiss, D.S. (2003). Predictors of Posttraumatic Stress Disorder and Symptoms in Adults: A Meta-Analysis. Psychological Bulletin, 129, $52-73$.

Paediatric Intensive Care Audit Network (2015).Annual Report (published November 2015), Universities of Leeds and Leicester.

Ruf, M., Schauer, E., Schauer, M., \& Elbert, T. (2008). Narrative exposure therapy for the treatment of traumatized children and adolescents (KidNET): from neurocognitive theory to field intervention. Child and Adolescent Psychiatric Clinics of North America, 17, 641-664. doi:10.1016/j.chc.2008.03.001

Robjant, K., \&Fazel, M. (2010). The emerging evidence for Narrative Exposure Therapy: a reviewClinical Psychology Review, 30, 1030-1039. doi:10.1016/j.cpr.2010.07.004

Samuel, V.M., Colville, G.A., Goodwin, S., Ryninks, K.\& Dean, S. (2015). The value of screening parents for their risk of developing psychological symptoms after PICU: a feasibility study evaluating a Pediatric Intensive Care Follow-Up Clinic. Pediatric Critical Care Medicine, 16, 808-813. doi:10.1097/PCC.0000000000000488

Schauer, M., Neuner, F., \& Elbert, T. (2011). Narrative Exposure Therapy: A short-term treatment for traumatic stress disorders (2nd Ed.). Oxford, UK: Hogrefe Publishing.

Tunick, R. A., Gavin, J. A., DeMaso, D. R., \& Meyer, E. C. (2013). Pediatric psychology 
critical care consultation: An emerging subspecialty. Clinical Practice in Pediatric Psychology, 1, 42-54.

Yule, W. (2014). Further thoughts on evaluating interventions for posttraumatic stress disorder in low and middle income countries. Intervention, 12, 286-289.

Zang, Y., Hunt, N., \& Cox T. (2014). Adapting narrative exposure therapy for Chinese earthquake survivors: a pilot randomised controlled feasibility study. $B M C$ Psychiatry, 14, 262.doi:10.1186/s12888-014-0262-3

Zigmond, A.S., \&Snaith, R.P. (1983). The hospital anxiety and depression scale. Acta Psychiatrica Scandinavica,67, 361-370. Zoellner, L.A., Feeny, N.C., Bittinger, J.N., Bedard-Gilligan, M.A., Slagle, D.M., Post, M., \& Chen, J.A. (2011). Teaching trauma-focused exposure therapy for PTSD: Critical clinical lessons for novice exposure therapists.Psychological Trauma: Theory, Research, Practice and Policy, 3,300-308. doi:10.1037/a0024642

\section{Footnotes}

${ }^{1}$ This case study is a composite designed to illustrate the NET approach and the issues that commonly arise in treatment, drawing on the experiences of the four parents seen.

${ }^{2}$ The quotes used in this section are taken verbatim from parents' NET accounts but are not attributed, in order to protect their identities. 


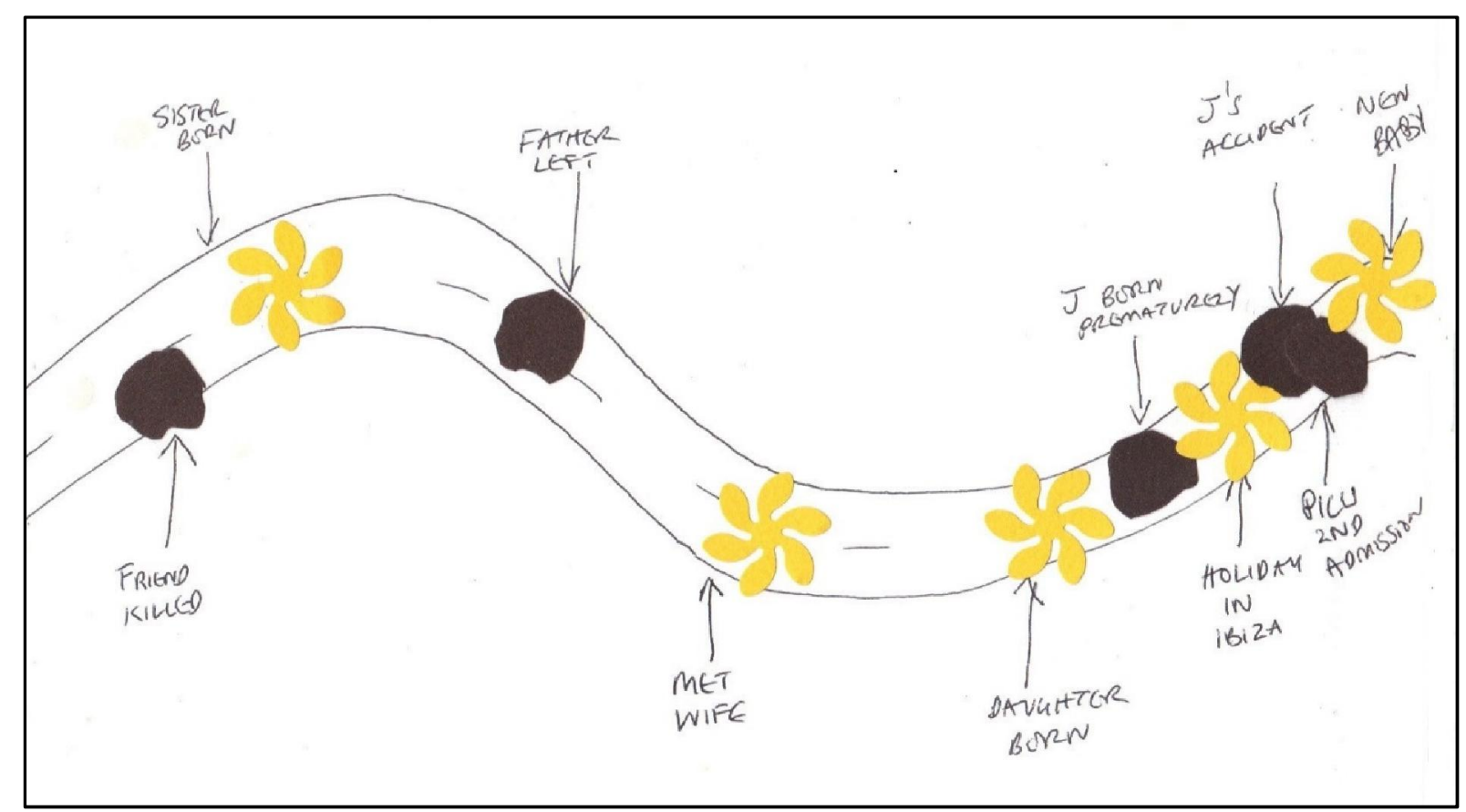

Figure 1.Steve's NET lifeline. Traumatic events are indicated by stones and particularly positive experiences by flowers. 
Table 1

Main sample characteristics

\begin{tabular}{|c|c|c|c|c|c|c|c|}
\hline \multirow[b]{2}{*}{ Case } & \multicolumn{2}{|c|}{ Age } & \multirow{2}{*}{$\begin{array}{c}\text { Discharge } \\
\text { Reason for referral to PICU }\end{array}$} & \multirow{2}{*}{$\begin{array}{l}\text { Number of } \\
\text { PICU stay }\end{array}$} & \multirow[b]{2}{*}{ Hospital stay } & \multirow[b]{2}{*}{ to treatment } & \multirow[b]{2}{*}{ NET sessions } \\
\hline & Parent & Child & & & & & \\
\hline Case 1 & $39 y$ & $18 \mathrm{~m}$ & Acute infection & $48 \mathrm{hrs}$ & $2 \mathrm{wks}$ & $19 \mathrm{~m}$ & 6 \\
\hline Case 2 & $32 y$ & $5 \mathrm{~m}$ & $\begin{array}{l}\text { Acute infection on top of chronic } \\
\text { hematological condition }\end{array}$ & $12 \mathrm{hrs}$ & $20 \mathrm{~m}$ & $12 \mathrm{~m}$ & 7 \\
\hline Case 3 & $36 y$ & $8 m$ & Chronic respiratory condition & $4 \mathrm{~m}$ & $12 \mathrm{~m}$ & $9 \mathrm{~m}$ & 10 \\
\hline Case 4 & $40 y$ & $4 y$ & Acute respiratory condition & $24 \mathrm{hrs}$ & $4 w k s$ & $6 \mathrm{~m}$ & 6 \\
\hline
\end{tabular}

Notes PICU=Paediatric Intensive Care Unit; NET=Narrative Exposure Therapy 
a) Post-traumatic stress (PDS)

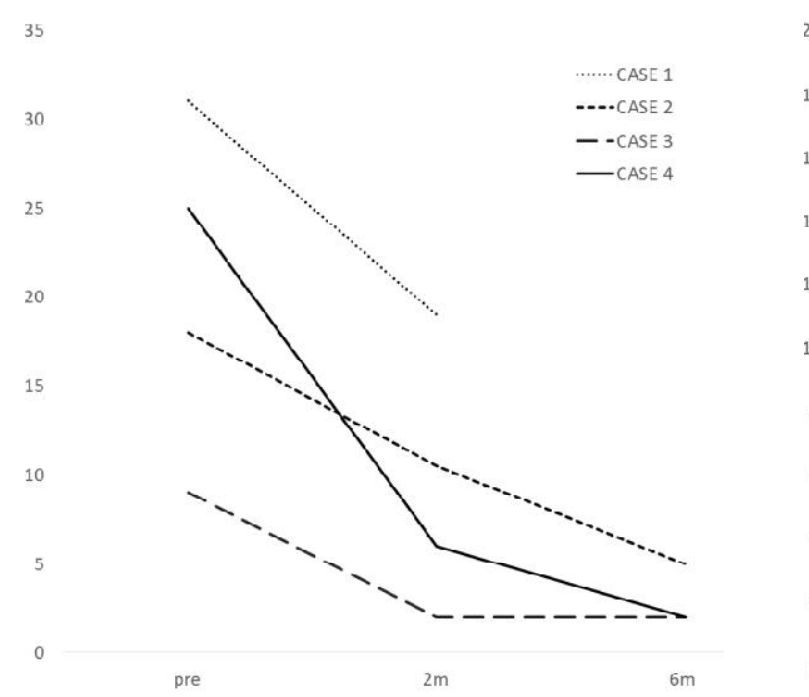

b) Anxiety (HADS)

20

8

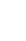

14

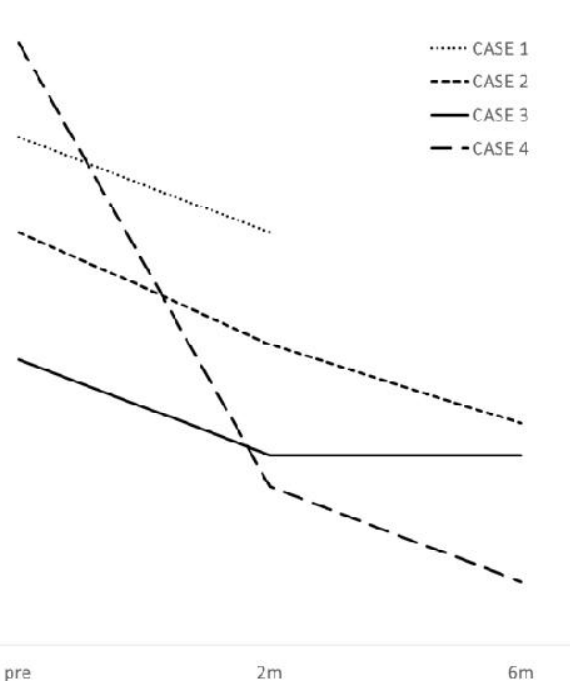

c) Depression (HADS)

20

18

14

12

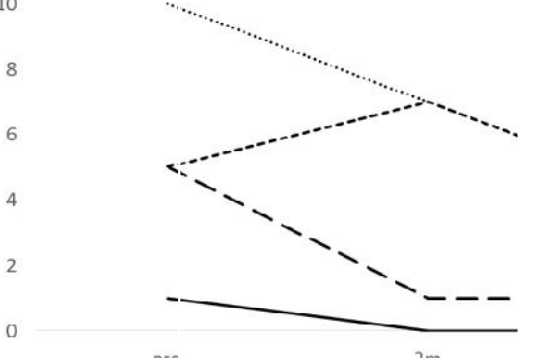

Figure 2.Parents' individual pre- and post-treatment scores.PDS=Posttraumatic Diagnostic Scale; HADS=Hospital Anxiety and Depression Scale. 